\title{
KASUS PT PANCA PUJI BANGUN DI SURABAYA DIKAITKAN DENGAN PASAL 91 AYAT (1) JO PASAL 185 UNDANG-UNDANG NOMOR 23 TENTANG KETENAGAKERJAAN
}

\author{
Eri Eka Sukarini \\ Universitas Wiralodra, Indramayu \\ Email: eri_ekasukarini@yahoo.com
}

\begin{abstract}
Abstrak
A work relationship is a relationship between a worker / laborer and an employer / employer that occurs after the employment agreement or based on a work agreement that has elements of work, wages and orders. Therefore, legal relations between workers and employers are bound by the existence of a work agreement. The purpose of this article is to report how to resolve industrial relations; to reveal wages according to the Labor Law; to report cases related to employment. The findings and discussion indicate that industrial relations disputes are differences of opinion which result in conflicts between employers or joint entrepreneurs with workers / laborers or trade unions because of disputes regarding rights, interests, termination of employment, and disputes between trade unions in one company . The procedures for resolving Industrial Relations Disputes (PHI) are in accordance with Law Number 2 Year 2004 concerning Settlement of Industrial Relations Disputes (PHI Law), namely: Bipartite Negotiations, Tripartite Negotiations, Mediation, Councils, Arbitration, Industrial Relations Court. From the case of PT Panca Puji Bangun regarding the wages of workers / laborers not in accordance with Surabaya City Minimum Wages, the case was resolved through the Industrial Relations Court (PHI).
\end{abstract}

Keywords : Work agreement, industrial relations, Panca Puji Bangun

\section{PENDAHULUAN}

Hubungan kerja adalah hubungan antara pekerja/buruh dengan pengusaha/pemberi kerja yang terjadi setelah adanya perjanjian kerja atau berdasarkan perjanjian kerja yang mempunyai unsur pekerjaan, upah dan perintah. Oleh karena itu, hubungan hukum antara pekerja dan pemberi kerja yang terikat dengan adanya perjanjian kerja. Perjanjian kerja sebagai sarana pendahulu sebelum berlangsungnya hubungan kerja, harus diwujudkan dengan sebaik-baiknya, dalam arti mencerminkan keadilan baik pengusaha maupun bagi pekerja. Karena keduanya akan terlibat dalam hubungan kerja.

Bentuk kepastian hukum dan perlindungan hukum bagi pekerja dilakukan melalui pelaksanaan dan penerapan perjanjian kerja. Karena dengan adanya perjanjian kerja diharapkan para pengusaha atau majikan tidak lagi memperlakukan para pekerja dengan 
sewenag-wenang, memutuskan hubungan kerja secara sepihak tanpa memperhatikan kebutuhan para pekerja serta ketentuan perundang-undangan yang berlaku.

Hubungan pengusaha dan pekerja/buruh didasarkan pada perjanjian kerja yang memuat syarat-syarat kerja serta hak dan kewajibannya masing-masing. Namun perjanjian kerja tersebut adakalanya ketidakharmonisan yang membuat salah satu pihak lebih menuntu pada haknya sehingga akan menimbulkan perselisihan yang berkepanjangan yang akan mengganggu proses produksi.

\section{Identifikasi Masalah}

a. Bagaimana cara penyelesaian hubungan industrial dalam ketenagakerjaan?

b. Bagaimana pengupahan pekerja/buruh menurut UU Ketenagakerjaan?

c. Kasus apa yang terjadi berkaitan dengan ketenagakerjaan?

\section{Tujuan Identifikasi}

a. Untuk mengetahui cara penyelesaian hubungan industrial.

b. Untuk mengetahui pengupahan menurut UU Ketenagakerjaan.

c. Untuk mengetahui kasus yang berkaitan dengan ketenagakerjaan. 


\section{HASIL DAN PEMBAHASAN}

\subsection{Cara Penyelesaian Hubungan Industrial}

Hubungan industrial adalah suatau system hubungan yang terbentuk antara para pelaku dalam proses produksi barang dan/atau jasa yang terdiri dari unsur pengusaha, pekerja/buruh dan pemerintah yang didasarkan pada nilai-nilai Pancasila dan UUD 1945. Di dalam system hubungan yang demikian, maka hubungan tersebut mendudukan antara pengusaha dan pekerja tersebut sama, atau sebagai mitra dimana pengusaha di dalam proses produksi memberikan modal (uang), sedangkan pekerja atau buruh memberikan tenaga dalam proses produksi tersebut ${ }^{1}$.

Hubungan pengusaha dan pekerja/buruh didasarkan pada perjanjian kerja yang memuat syarat-syarat kerja serta hak dan kewajibannya masing-masing. Namun perjanjian kerja tersebut adakalanya ketidakharmonisan yang membuat salah satu pihak lebih menuntu pada haknya sehingga akan menimbulkan perselisihan yang berkepanjangan yang akan mengganggu proses produksi.

Maka yang dimaksud dengan perselisihan hubungan industrial adalah perbedaan pendapat yang mengakibatkan pertentangan antara pengusaha atau gabungan pengusaha dengan pekerja/buruh atau serikat pekerja/serikat buruh karena adanya perselisihan mengenai hak, kepentingan, pemutusan hubungan kerja, dan perselisihan antara serikat pekerja/serikat buruh dalam satu perusahaan ${ }^{2}$. Penyelesaian perselisihan hubungan industrial diatur dalam Undang-Undang Nomor 2 Tahun 2004.

Dalam perselisihan hubungan industrial ada 4 jenis, yaitu: ${ }^{3}$

1. Perselisihan hak adalah perselisihan yang timbul karena tidak dipenuhinya hak, akibat adanya perbedaan pelaksanaan atau penafsiran peraturan perusahaan atau perjanjian kerja bersama.

2. Perselisihan kepentingan adalah perselisihan yang timbul dalam hubungan kerja karena tidak adanya kesesuaian pendapat mengenai pembuatan dan/atau perubahan syarat-syarat kerja yang ditetapka dalam perjanjian kerja atau peraturan perusahaan atau perjanjanjian kerja bersama.

\footnotetext{
${ }^{1}$ Aris Supomo, 2017, Hukum Perburuhan/Ketenaagkerjaan, K-Media, Yogyakarta, hlm. 36

2 Ibid hlm. 38

${ }^{3}$ Pasal 1 Undang-Undang Nomor 2 Tahun 2004 Tentang Penyelesaian Hubungan Industrial
} 
3. Perselisihan pemutusan hubungan kerja adalah perselisihan yang timbul karena tidak adanya kesesuaian pendapat mengenai pengakhiran hubungan kerja yang dilakukan oleh salah satu pihak.

4. Perselisihan antar serikat perja/buruh adalah perselisihan antara serikat pekerja/buruh dengan serikat pekerja/buruh lain hanya dalam satu perusahaan, karena tidak adanya kesusaian paham mengenai keanggotaan, pelaksanaan hak dan kewajiban keserikat pekerjaan.

Peraturan perusahaan sebagai sarana penunjang hubungan industrial dalam melaksanakan hubungan kerja harus membuat peraturan perusahaan secara tertulis yang memuat syarat-syarat kerja dan tata tertib perusahaan. Masa berlakunya peratutan perusahaan adalah 2 tahun dan wajib diperbarui setelah masa berlakunya berakhir. Selama peraturan perusahaan berlaku tidak boleh dilakukan perubahan kecuali atas kesepakatan antara wakilpekerja dengan pengusaha dan perubahm tersebut harus mendapat pengesahan oleh mentri atau pejabat yang dituntuk Yang dimuat dalam peraturan perusahaan adalah: ${ }^{4}$

a. Hak dan kewajiban pengusaha

b. Hak dan kewajiban pekerja/buruh

c. Syarat-syarat kerja

d. Tata tertib perusahaan

e. Jangka waktu berlakunya

Tata cara penyelesaian Perselisihan Hubungan Industrial (PHI) sesuai UU Nomor 2 Tahun 2004 tentang Penyelesaian Perselisihan Hubungan Industrial (UU PHI), yaitu: 5

\section{Perundingan Bipartit}

Perundingan dua pihak antara pengusaha atau gabungan pengusaha dan buruh atau serikat buruh. Bila dalam perundingan bipartit mencapai kata sepakat mengenai penyelesaiannya maka para pihak membuat perjanjian bersama yang

\footnotetext{
${ }^{4}$ Aris Supomo, Op.cit 34

${ }^{5}$ https://bplawyers.co.id/2017/03/23/3-tata-cara-penyelesaian-perselisihan-hubungan-industrial-yangwajib-anda-ketahui/, diakses tanggal 18 Desember 2018
} 
kemudian didaftarkan pada PHI setempat. Namun apabila dalam perundingan tidak mencapai kata sepakat, maka para pihak yang berselisih harus melalui prosedur penyelesaian Perundingan Tripartit.

\section{Perundingan Tripartit}

Perundingan antara pekerja, pengusaha dengan melibatkan pihak ketiga sebagai fasilitator dalam penyelesaian PHI diantara pengusaha dan pekerja. Perundingan tripartit bisa melalui mediasi, konsiliasi dan arbitrase.

\section{a. Mediasi}

Penyelesaian melalui musyawarah yang ditengahi oleh seorang atau lebih mediator dari pihak Depnaker, yang antara lain mengenai perselisihan hak, kepentingan, PHK dan perselisihan antar serikat buruh dalam satu perusahaan. Dalam mediasi, bilamana para pihak sepakat maka akan dibuat perjanjian bersama yang kemudian akan didaftarkan di PHI.

Namun bilamana tidak ditemukan kata sepakat, maka mediator akan mengeluarkan anjuran secara tertulis. Jika anjuran diterima, kemudian para pihak mendaftarkan anjuran tersebut ke PHI. Di sisi lain, apabila para pihak atau salah satu pihak menolak anjuran maka pihak yang menolak dapat mengajukan tuntutan kepada pihak yang lain melalui PHI.

\section{b. Konsiliasi}

Penyelesaian melalui musyawarah yang ditengahi oleh seorang konsiliator (yang dalam ketentuan UU PHI adalah pegawai perantara swasta bukan dari Depnaker sebagaimana mediasi) yang ditunjuk oleh para pihak. Seperti mediator, Konsiliator berusaha mendamaikan para pihak, agar tercipta kesepakatan antar keduanya.

Bila tidak dicapai kesepakatan, Konsiliator juga mengeluarkan produk berupa anjuran.

\section{c. Arbitrase}

Penyelesaian perselisihan di luar PHI atas perselisihan kepentingan dan perselisihan antar serikat buruh dalam suatu perusahaan dapat ditempuh melalui kesepakatan tertulis yang berisi bahwa para pihak sepakat untuk menyerahkan perselisihan kepada para arbiter. Keputusan arbitrase merupakan keputusan final dan mengikat para pihak yang berselisih, dan 
para arbiter tersebut dipilih sendiri oleh para pihak yang berselisih dari daftar yang ditetapkan oleh Menteri Tenaga Kerja.

\section{Pengadilan Hubungan Industrial}

Bagi pihak yang menolak anjuran mediator dan juga konsiliator, dapat mengajukan gugatan ke PHI. Tugas PHI antara lain mengadili perkara Perselisihan Hubungan Industrial, termasuk perselisihan PHK, serta menerima permohonan dan melakukan eksekusi terhadap Perjanjian Bersama yang dilanggar.

\subsection{Pengupahan Pekerja/Buruh}

Berdasarkan pasal 1 angka 30 UU Nomor 13 Tahun 2003 disebutkan bahwa yang dimaksud dengan upah adalah hak pekerja/buruh yang diterima dan dinyatakan dalam bentuk uang sebagai imbalan dari pengusaha atau pemberi kerja kepada pekerja atau buruh yang ditetapkan menurut suatu perjanjian kerja, kesepakatan atau peraturan perundang-undangan, termasuk tunjangan bagi pekerja,buruh dan keluarganya atas suatu pekerjaan dan/atau jasa yang telah dan/atau akan dilakukan ${ }^{6}$. Komponen-komponen upah terdiri atas: upah pokok, tunjangan tetap, dan tunjangan tidak tetap.

Kaitannya dengan pengupahan ini pada dasarnya pengusaha tidak boleh memberikan upah di bawah upah minimum. Upah minimum terdiri atas ${ }^{7}$ :

a. Upah minimum provinsi/kabupaten yaitu upah minimum yang berlaku pada provinsi/kabupaten tertentu.

b. Upah minimum sektoral regional yaitu upah minimum yang berlaku pada sektor usaha tertentu pada daerah tertentu tidak boleh lebih rendah dari upah minimum daerah yang besangkutan.

Dalam hal pengusaha mempekerjakan pekerja melebihi waktu kerja yaitu 7 jam sehari dan 40 jam seminggu untuk 6 hari kerja atau 8 jam sehari dan 40 jam seminggu untuk 5 hari, maka pengusaha wajib membayar upah lembur. Besarnya

${ }^{6}$ Pasal 1 angka (30) Undang-undang Nomor 13 Tahun 2003 tentang Ketenagakerjaan

${ }^{7}$ Aris Supomo, Op.cit., 21 
upah lembur ditentukan dalam Keputusan Menteri Tenaga Kerja No...Kep72/MEN/1984 tentang dasar perhitungan upah lembur ${ }^{8}$.

Pelanggaran terhadap ketentuan tersebut dapat diancam pidana kurungan paling singkat 1 bulan dan paling lama 12 bulan dan/atau denda paling sedikit $\mathrm{Rp}$ 10.000.000,- (sepuluh juta rupiah) dan sanksi itu tidak menghilangkan kewajiban bagi pengusaha untuk membayar hak-hak dan/atau ganti kerugian kepada pekerja ${ }^{9}$.

${ }^{8}$ Aris Supomo, Op.cit., 22

${ }^{9}$ Aris Supomo, Op.cit., 23 


\subsection{Kasus Yang Berkaitan Dengan Ketenagakerjaan}

Kasus PT Puri Panca Pujibangun, Surabaya, yang terjadi tahun 2004-2010 yang memberi upah di bawah Upah Minimum Kabupaten (UMK).

Kasus bermula saat PT Panca Puji Bangun itu mempekerjakan 35 orang karyawan di pabriknya di Jalan Tanjung Anom, Surabaya pada 2004. Nah, kurun 2004-2010, PT Panca Puji Bangun menggaji buruhnya di bawah UMR. Yaitu:

1. Upah terendah yaitu Rp 680 ribu sebanyak 10 orang.

2. Upah tertinggi sebesar Rp 1,2 juta.

3. Selain itu, buruh mendapatkan tunjangan tidak tetap yang besarnya bervariasi, berupa yang hadir, uang makan dan uang premi.

Salah satu karyawan yang bernama Yudi Santoso mendapatkan upah:

1. Gaji pokok Rp 300 ribu.

2. Tunjangan keluarga Rp 30 ribu.

3. Tunjangan rumah $\mathrm{Rp} 150 \mathrm{ribu.}$

4. Tunjangan transportasi Rp 6 ribu per kedatangan.

5. Uang premi Rp 50 ribu.

Gaji di atas juga dirasakan tak jauh beda oleh M Setiyo Budi. Kala itu, UMR Kota Surabaya sebesar Rp 934.500.

Pada 2007, PT Panca Puji Bangun merumahkan Yudi dan Setiyo dengan alasan kinerja keduanya di bawah standar. Tidak terima dengan hal itu, Yudi dan Setiyo melaporkan PT Panca Puji Bangun ke Dinas Ketenagakerjaan setempat.

Bagoes selaku Direktur PT Panca Puji Bangun dilaporkan telah melanggar Pasal 91 ayat 1 jo Pasal 185 ayat 3 UU Nomor 13 Tahun 2003 tentang Ketenagakerjaan. Pasal itu berbunyi:

Pasal 91 ayat 1 berbunyi:

Pengaturan pengupahan yang ditetapkan atas kesepakatan antara pengusaha dan pekerja/buruh atau serikat pekerja/serikat buruh tidak boleh lebih rendah dari ketentuan pengupahan yang ditetapkan peraturan perundang-undangan yang berlaku.

Adapun Pasal 185 berbunyi:

1. Barang siapa melanggar ketentuan sebagaimana dimaksud dalam Pasal 
42 ayat (1) dan ayat (2), Pasal 68, Pasal 69 ayat (2), Pasal 80, Pasal 82, Pasal 90 ayat (1), Pasal 143, dan Pasal 160 ayat (4) dan ayat (7), dikenakan sanksi pidana penjara paling singkat 1 tahun dan paling lama 4 tahun dan/atau denda paling sedikit Rp 100 juta dan paling banyak Rp 400 juta.

2. Tindak pidana sebagaimana dimaksud dalam ayat (1) merupakan tindak pidana kejahatan.

Kasus pun bergulir hingga ke pengadilan. Pada 30 Maret 2010, jaksa menuntut Bagoes selama 18 bulan penjara. Gayung bersambut. Pengadilan Negeri (PN) Surabaya menghukum Bagoes selama 1 tahun penjara karena menggaji karyawannya di bawah UMR. Putusan itu dikuatkan Pengadilan Tinggi (PT) Surabaya pada 13 April 2010 dan kasasi pada 8 November 2011.

Tidak terima dengan putusan itu, Bagoes mengambil langkah hukum luar biasa yaitu mengajukan peninjauan kembali (PK). Bagoes berdalih dirinya hanyalah karyawan di perusahaan tersebut. Tapi apa kata MA?

"Menolak permohonan pemohon PK," ucap majelis yang terdiri dari Timur Manurung, Prof Dr Surya Jaya dan Suhadi.

Alasan Bagoes yang mengaku hanya karyawan ditepis MA. Sebab, sebagai direktur, mempunyai kemampuan untuk menyatakan sistem penggajian di perusahaan telah melanggar perundangan yang berakibat pidana, yang tidak boleh dilanggar oleh perusahaan dan harus dipatuhi.

"Terpidana tidak dapat mengajukan bukti pernah mengajukan keberatannya kepada pemilik perusahaan, agar penggajian karyawan diperbaiki sesuai aturan perundangan, karenanya permohonan PK tidak dapat dibenarkan," pungkas majelis pada 5 Mei $2015 .^{10}$

\footnotetext{
${ }^{10}$ https://news.detik.com/berita/d-3486709/upah-buruh-di-bawah-umr-direktur-disurabaya-dipenjara-1-tahun, diakses tanggal 18 Desember 2018
} 
Dilihat dari kasus di atas, PT Puri Panca Pujibangun telah melakukan wanprestasi karena pekerja/buruh diberikan upah tidak sesuai UMK, dan 2 orang pekerja dirumahkan dengan alasan kinerja mereka yang kurang baik. PT Puri Panca Pujibangun tersebut telah melanggar perjanjian kerja antara pekerja/buruh dengan pengusaha yang tertuang dalam peraturan perusahaan (PP), yaitu hak dan kewajiban pekerja. Oleh karena itu, penyelesaian perselisihan hubungan industrial dilakukan melalui proses pengadilan hubungan industrial dan telah memiliki kekuatan hokum yang tetap dengan putusan bahwa Bagoes selaku Direktur PT Panca Puji Bangun dihukum penjara 1 tahun. Putusan itu dikuatkan Pengadilan Tinggi (PT) Surabaya pada 13 April 2010 dan kasasi pada 8 November 2011. 


\section{Kesimpulan}

Perselisihan hubungan industrial adalah perbedaan pendapat yang mengakibatkan pertentangan antara pengusaha atau gabungan pengusaha dengan pekerja/buruh atau serikat pekerja/serikat buruh karena adanya perselisihan mengenai hak, kepentingan, pemutusan hubungan kerja, dan perselisihan antara serikat pekerja/serikat buruh dalam satu perusahaan.

Tata cara penyelesaian Perselisihan Hubungan Industrial (PHI) sesuai UU Nomor 2 Tahun 2004 tentang Penyelesaian Perselisihan Hubungan Industrial (UU PHI), yaitu:

1. Perundingan Bipartit

2. Perundingan Tripartit
a. Mediasi
b. Konsiliasi
c. Arbitrase

3. Pengadilan Hubungan Industrial

Dari kasus PT Panca Puji Bangun mengenai pemberian upah pekerja/buruh tidak sesuai Upah Minimun Kota Surabaya, perkara tersebut diselesaikan melalui Pengadilan Hubungan Industrial (PHI). 


\section{DAFTAR PUSTAKA}

Aris Supomo, 2017, Hukum ketenagakerjaan/Perburuhan, K-Media, Yogyakarta.

Undang-Undang Nomor 13 Tahun 2003 Tentang Ketenagakerjaan.

Undang-Undang Nomor 2 Tahun 2004 Tentang Penyelesaian Perselisihan Hubungan Industrial.

https://bplawyers.co.id/2017/03/23/3-tata-cara-penyelesaian-perselisihanhubungan-industrial-yang-wajib-anda-ketahui/.

https://news.detik.com/berita/d-3486709/upah-buruh-di-bawah-umr-direktur-disurabaya-dipenjara-1-tahun. 